\title{
SHORT-WAVELENGTH TECHNOLOGY AND THE POTENTIAL FOR DISTRIBUTED NETWORKS OF SMALL RADAR SYSTEMS
}

by David Mclaughlin, David Pepyne, V. Chandrasekar, Brenda Philips, James Kurose, Michael Zink, Kelvin Droegemeier, Sandra Cruz-Pol, Francesc Junyent, Jerald Brotzge, David Westbrook, Nitin Bharadwa, Yanting Wang, Eric lyons, Kurt Hondl, Yuxiang liu, Eric Knapp, Ming Xue, Anthony Hopf, Kevin Kloesel, Alfred DeFonzo, Pavlos Kollias, Keith Brewster, Robert Contreras, Brenda Dolan, Theodore Djaferis, Edin Insanic, Stephen Frasier, and Frederick Carr

Dense networks of small radars - unlike today's large installations - can defeat Earth curvature blockage, thus providing more low-altitude data and meeting the diverse needs of end users.

$\mathrm{L}$ ong-range microwave radar networks are an important part of the weather forecasting and warning infrastructure used by many nations today. The observing capabilities of these networks have improved considerably over the past 60 years as new technologies-such as coherent high-power transmitters, solid-state electronics, Doppler and dual-polarization signal processing, open software architecture, and improved data dissemination and display technologies-have been developed and incorporated into the system design. Taking the U.S. weather radar network as an example, it is generally agreed that the improved performance and coverage of the Weather Surveillance Radar-1988 Doppler [WSR-88D; Next Generation Weather Radar (NEXRAD)] system, relative to the predecessor WSR-57 and WSR-74 systems, has led to significant improvement in the short-range forecasting and warning of severe thunderstorms, tornadoes, and flash floods (Serafin and Wilson 2000; National Research Council 1995). Despite significant capability and continual improvement, one fundamental limitation of today's weather radar networks-all of which are composed of widely spaced radars-is the
Affiliations: McLaughlin, Pepyne, Philips, Kurose, Zink, Westbrook, Lyons, Knapp, Hopf, DeFonzo, Contreras, DJaferIs, Insanić, ANd FrasierUniversity of Massachusetts, Amherst, Amherst, Massachusetts; Chandrasekar, Junyent, BharadwaJ, Wang, Liu, and Dolan-Colorado State University, Fort Collins, Colorado; Droegemeier, Brotzge, Xue, KLoESEL, BREWSTER, AND CARR-University of Oklahoma, Norman, Oklahoma; CRUz-PoL-University of Puerto Rico, Mayagüez, Puerto Rico; HondL-National Severe Storms Laboratory, Norman, Oklahoma; Kolılas-McGill University, Montreal, Quebec, Canada
CORRESPONDING AUTHOR: David Pepyne, University of Massachusetts, I5I Holdsworth Way, Amherst, MA 01003 E-mail: pepyne@ecs.umass.edu

The abstract for this article can be found in this issue, following the table of contents. DOI:10.1175/2009BAMS2507.I

In final form 21 April 2009

(02009 American Meteorological Society 
inability to observe the lower part of the atmosphere due to the Earth's curvature and terrain blockage. Continuing with the U.S. example, the radars comprising the NEXRAD system are spaced $\sim 230 \mathrm{~km}$ apart in the eastern United States and $\sim 345 \mathrm{~km}$ in the western United States. This spacing prevents the system from observing more than $70 \%$ of the troposphere below 1-km altitude above ground level (AGL). A National Research Council (1995) study investigated the adequacy of this network relative to the detection and warning of a variety of weather phenomena, including landfalling hurricanes, supercells, mesocyclones, tornado vortices, microbursts, and various types of precipitation, including snowfall. This study found that the WSR-88D network provides superior forecasting and warning capability compared with the predecessor WSR-57 and WSR-74 systems. Nevertheless, incomplete low-level coverage and limited spatial resolution at long distance impedes the ability of this system to identify and detect small tornadoes and other finescale weather features. Current detection algorithms based on data from this system produce false-alarm rates that are higher than desirable (National Research Council 2002, p. 19); for example, the probability of false alarms for tornado warnings today is $\sim 75 \%$ (with a probability of detection of $\sim 72 \%$ and 14 -min lead time; data for the period 1 October 2007-30 September 2008). Westrick et al. (1999) assess the effect of limited low-level WSR-88D coverage for detection and quantitative precipitation estimation over the West Coast region. This study concluded that, as a result of significant terrain blockage in that region combined with the shallow depth of precipitation during cold seasons and low melting levels, $67 \%-75 \%$ percent of the land surface in the region has inadequate radar coverage to support quantitative precipitation estimation.

The radars in the WSR-88D network, like those in other operational civil infrastructure radar networks deployed around the world, are physically large highpower systems. Designed for long-range (hundreds of kilometers) coverage through heavy precipitation, these radars must operate at radar wavelengths not be subject to substantial attenuation. ${ }^{1}$ This necessitates the use of large antennas to achieve the narrow beamwidth needed for kilometer-scale spatial resolution throughout the coverage region. ${ }^{2}$ The radars use high-power transmitters to meet minimum sensitivity requirements and large mechanically scanned antennas that require dedicated land, towers, and other support infrastructure. The acquisition cost for each site-including radar equipment, land, and other installation costs-is approximately $\$ 10$ million (U.S. dollars) per radar, and the annual per-radar operating and maintenance cost has been estimated to be $\$ 500,000$ (National Research Council 2008, p. 12). The large physical size of these systems combined with potential environmental effects limits the availability of potential sites. Moreover, scanning of the WSR-88D antenna below $0.5^{\circ}$ elevation is prohibited because of the public's concerns about radiation safety. Leone et al. (1989) describe the site selection procedure for the WSR-88D radar installations. The system is jointly owned by the National Weather Service (NWS), Department of Defense (DoD), and Federal Aviation Administration (FAA), and each of these agencies' established criteria for siting the radars based on factors that include population distribution, climatology, approach and travel directions of severe weather, locations of airports and airways, and the location of NWS forecast offices and high-priority military and civilian facilities. The strategy for deploying national radar networks such as this is to judiciously attempt to site radars where low-altitude coverage is most needed while simultaneously minimizing the number of radars in the network as a means of controlling the life cycle costs of the system.

The increasing need for improved coverage at low altitudes, particularly in the planetary boundary layer, is articulated in several recent reports produced by federal agencies and National Research Council committees (e.g., National Research Council 2002, 2004, 2008, 2009; OFCM 2006). These reports reflect the emerging need for improved low-altitude radar coverage to support numerous applications ranging from improved hazardous weather forecasting and warning to wind mapping for fire fighting and tracking airborne toxic release to monitoring bird migration to enhanced support for roadway weather. Beyond weather, the DoD's Strategy for Homeland Defense and Civil Support report (DoD 2005, p. 26) notes, "the nation will need to develop an advanced capability to replace the current generation of radars to improve

\footnotetext{
${ }^{1}$ The low-attenuating wavelengths of $10 \mathrm{~cm}$ (S-band) and $5 \mathrm{~cm}$ (C-band) are used for long-range radars.

${ }^{2}$ The achievable cross-range spatial resolution (azimuth and elevation) is dictated by the antenna beamwidth, which for the WSR-88D NEXRAD radars is just under $1^{\circ}$. A $1^{\circ}$ beamwidth gives a cross-range resolution of $2.8 \mathrm{~km}$ at $160-\mathrm{km}$ range. The planned NEXRAD "super resolution" upgrade will use signal-processing techniques to reduce the effective beamwidth (Torres and Curtis 2006), improving the azimuth resolution to $1.4 \mathrm{~km}$ at $160 \mathrm{~km}$.
} 
tracking and identification of low-altitude threats." Such needs cannot be met with networks composed of long-range radars because of the fundamental inability of such systems to provide comprehensive low-altitude coverage.

The National Science Foundation (NSF) Engineering Research Center (ERC) for Collaborative Adaptive Sensing of the Atmosphere (CASA) is researching a new weather hazard forecasting and warning technology based on low-cost, dense networks of radars that operate at short range, communicate with one another, and adjust their sensing strategies in direct response to the evolving weather and to changing user needs (McLaughlin et al. 2005; Kurose et al. 2006; Philips et al. 2007). In contrast to the large weather radars in today's operational networks, such as NEXRAD having 9-m-diameter antennas and radar spacing of hundreds of kilometers, the antennas in dense networks are expected to be $1 \mathrm{~m}$ in size, with the radars spaced tens of kilometers apart. The small size of these radars allows them to be placed on existing infrastructure elements such as communication towers and rooftops (Fig. 1). The short range of the radars defeats the Earth curvature blocking problem, enabling these networks to comprehensively map damaging winds and heavy rainfall from the tops of storms down to the boundary layer beneath the view of today's networks. In addition to enabling comprehensive low-altitude observations, short-range operation offers the potential for significant improvements in resolution and update times compared to today's state-of-theart radars. These improvements, in turn, enable a better characterization of storm morphology and analysis, offering the potential for improvements in weather hazard forecasting and warning. In addition to the radars and their associated hardware and data communication infrastructure, a new generation of meteorological software is being developed to target the resources in these radars to simultaneously support emergency managers and government and private industry organizations that need weather data for making critical decisions.

A dense network of $\sim 10,000$ such radars would be required to blanket the contiguous United States at $30-\mathrm{km}$ radar spacing. These radars would require less than $100 \mathrm{~W}$ of average transmitter power, yet they would be capable of mapping storms with $<1-\mathrm{km}$ spatial resolution throughout the entire tropospherefrom the critical low-troposphere "gap" region up to the tops of storms. Such networks thus have the potential to supplement, or perhaps replace, the large networks in use today. Blanket deployment of thousands of small radar nodes across an entire nation is but one of several possible future deployment strategies for this technology. Additional strategies would potentially include selective deployment of smaller networks in heavily populated areas, geographic regions particularly prone to wind hazards or flash floods, valleys within mountainous regions, or in specific regions where it is particularly important to improve observation of low-level meteorological phenomena. Cost, maintenance, and reliability issues as well as aesthetics and radiation safety concerns motivate the use of small ( $\sim$-m diameter) antennas and low-power transmitters that could be installed on either low-cost towers or existing infrastruc- 
ture elements (such as rooftops or communication towers). ${ }^{3}$ The cost to deploy and operate a dense network will include both the up-front cost of the radars and the recurring costs to maintain them, buy or rent land and space on towers/rooftops, and provide for data communication between the radars, operations and control centers, and users. These costs, in addition to numerous technological and system-level trade-offs, need to be balanced to ultimately develop an effective system design.

The Engineering Research Center for CASA is a partnership among academic, industrial, and government participants (www.casa.umass.edu). The center aims to lay the fundamental and technological foundations for dense, adaptive radar networks; conduct proof-of-concept demonstrations using field-scale test beds deployed in hazard-prone areas; and ultimately transition the concepts and technologies into practice through commercialization and technology transfer mechanisms. Projects undertaken within the center include the design and fabrication of lowpower solid-state radars, new hazard-detection algorithms that make use of the data, and the creation of an open-system software architecture for organizing hardware and software components and interfacing with multiple groups of data users. The first test bed, comprising a network of four small radars, was installed during winter/spring 2006 on telecommunication towers in southwest Oklahoma in a region frequented by tornadoes and severe thunderstorms. A user group composed of emergency managers and public and private sector weather forecasters is included in the CASA team and is participating in the designing and testing of the system.

This paper discusses key system-level trade-offs associated with this new approach to weather radar network design and documents key aspects of CASA's first test bed deployment as a proof of concept. As background, we begin in the "Sensing gap" section by characterizing the low-altitude sensing gap that limits the coverage of any network composed of widely spaced radars, and we show how a dense network of closely spaced radars overcomes this limitation. Placing radars close together (a few tens of kilometers apart) and operating them as a network substantially

\footnotetext{
${ }^{3}$ The average equivalent isotropic radiated power (EIRP) of such radars would be $48 \mathrm{dBW}$, compared to $76 \mathrm{dBW}$ for the WSR-88D radars. Given the Federal Communication Commission's (FCC's) $1 \mathrm{~mW} \mathrm{~cm}{ }^{-2}$ microwave radiation safety specification, such small radars are radiation safe at ranges beyond $20 \mathrm{~m}$, whereas WSR-88D radiation safety begins at $530 \mathrm{~m}$.
}

reduces the radar's physical size and transmitted power compared to today's weather radar designs. In the "Short-wavelength engineering design trade-offs" section, we describe the trade-offs related to choice of wavelength, antenna size, power level, and radar spacing for this concept. The "Networked operation" section presents results from CASA's Oklahoma test bed network and highlights the collaborative, adaptive radar coordination system developed to support networked X-band radar operation. The approach to weather radar described in this paper is maturing and although the Oklahoma test bed trials look promising, additional work needs to be done to prove that this concept can be realized efficiently and effectively as a new technology. Accordingly, the "Open issues" section addresses cost issues, mentions some potential shortcomings of this approach, and discusses open issues that need to be further investigated. Pointers are also given to publications that describe aspects of this concept in greater detail. This paper concludes with a summary.

SENSING GAP. Figures $2 \mathrm{a}$ and $2 \mathrm{~b}$ show NEXRAD coverage at altitudes of $3 \mathrm{~km}(\sim 10,000 \mathrm{ft})$ and $1 \mathrm{~km}(\sim 3,200 \mathrm{ft})$ AGL, respectively [data courtesy of I. Graffman, National Oceanic and Atmospheric Administration/NWS/Office of Science and Technology; see also Maddox et al. (2002)]. Coverage at 3-km altitude is comprehensive east of the Rocky Mountains, where the spacing between radars is
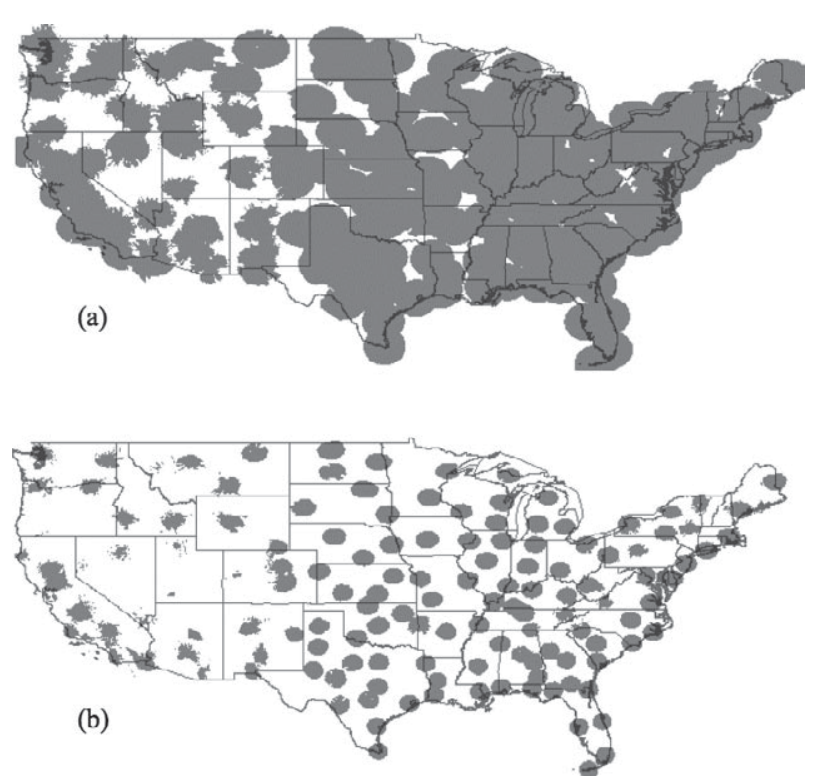

FIG. 2. NEXRAD coverage at (a) 3 and (b) I km AGL. These plots are the center of the beam at $0.5^{\circ}$ elevation (NEXRAD lowest allowed tilt, by policy). (Coverage data courtesy of I. Graffman, NOAA/NWS/OST.) 
$\sim 230 \mathrm{~km}$. In the western part of the country, where the representative spacing between radars is $\sim 345 \mathrm{~km}$, coverage gaps exist as a result of both Earth curvature blockage and terrain blockage (National Research Council 1995). Coverage is poor at $1-\mathrm{km}$ altitude throughout the entire conterminous United States (CONUS) except in those regions in close proximity to the radar antennas.

The only way to provide more comprehensive coverage of the lower troposphere (e.g., $<3-\mathrm{km}$ AGL) is to decrease the spacing between the radars. Figure 3 plots the percentage of the volume in a thin layer above ground level covered versus radar spacing for different altitudes (solid curves). ${ }^{4}$ Also plotted is the number of radars needed for blanket CONUS coverage versus radar spacing (dashed line). The vertical bars at 230 and $345 \mathrm{~km}$ are the two representative NEXRAD spacings discussed above. As shown in the plots, decreasing the spacing between the radars increases the low-altitude coverage (solid lines show an increase toward $100 \%$ with decreasing radar separation); the blockage due to the Earth's curvature is "defeated" when the radar spacing is reduced to $\sim 50 \mathrm{~km}$ or less. The next section discusses the radar engineering trade-offs that motivate consideration of small X-band radars spaced $\sim 30 \mathrm{~km}$ apart, a spacing at which, as shown in Fig. 3, 10,000 radars would be required for complete CONUS coverage. The beamwidth for these radars will be about $1.8^{\circ}$. As shown in Fig. 4, the entire beam of such a radar at its lowest tilt of $0.9^{\circ}$ is below $1 \mathrm{~km}$. The center of the beam is $0.5 \mathrm{~km}$ above ground level at $30 \mathrm{~km}$; the worst-case beam height is lower than this value when the radars are operated in a network, as we describe in the "Networked operation" section.

\section{SHORT-WAVELENGTH ENGINEERING} DESIGN TRADE-OFFS. Cost-effective deployment of dense networks composed of large numbers of radars requires that the acquisition, deployment,

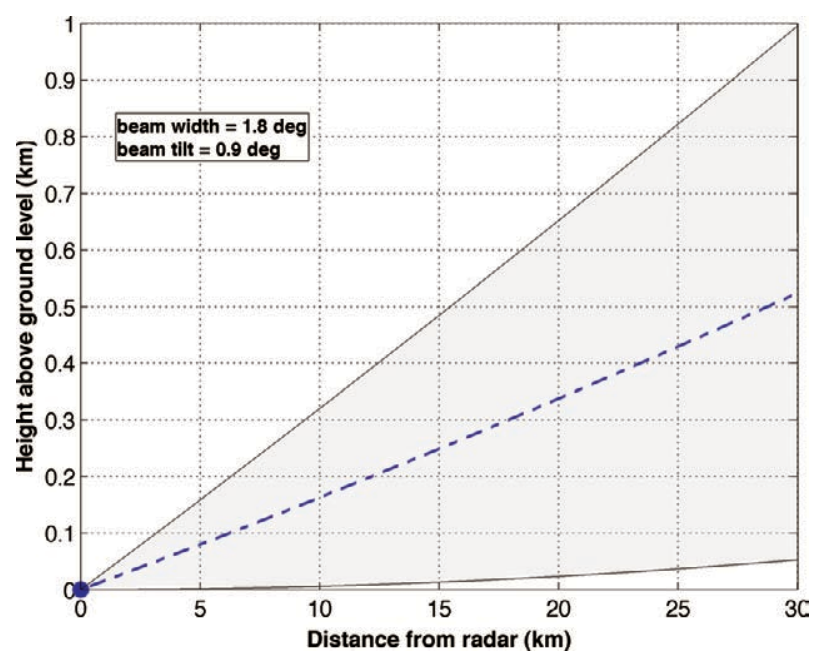

FIG. 4. Beam height AGL for a small (I-m antenna) short wavelength $(X$-band) radar. The shaded region is the coverage by the $1.8^{\circ}$ beam at $0.9^{\circ}$ elevation angle. The dotted line is the center of the beam. At this lowest tilt, the entire beam is below $1 \mathrm{~km}$ over a $30-\mathrm{km}$ range.

and recurring costs be substantially smaller than the per-radar costs of today's high-power radar designs. Rather than acquiring acre-size land plots and de-

\footnotetext{
${ }^{4}$ The curves are idealized, smooth Earth approximations. The plots assume a lowest beam tilt angle of $0.5^{\circ}-$ the minimum tilt angle for a NEXRAD radar. Increasing the minimum tilt angle shifts the curves to the left; the $0.9^{\circ}$ minimum beam tilt angle for the radars in the CASA test bed network discussed in the "Short-wavelength engineering design trade-offs" section for example, shifts, the break point in the 300-m curve from $\sim 50$ to $\sim 30 \mathrm{~km}$.
} 


\begin{tabular}{|c|c|c|}
\hline \multicolumn{3}{|c|}{ TABLE I. Two-way attenuation (dB) through $\mathbf{~} \mathbf{~ k m}$ of rain. } \\
\hline Rain rate $\left(\mathbf{m m ~ h} \mathbf{~}^{-1}\right)$ & S-band $(\mathbf{1 0} \mathbf{~ c m})$ & X-band $(3.2 \mathbf{~ c m})$ \\
\hline 4 & 0.03 & 1.10 \\
\hline 20 & 0.14 & 7.79 \\
\hline 40 & 0.27 & 18.09 \\
\hline 100 & 0.65 & 55.13 \\
\hline
\end{tabular}

S-band to attenuation at the shorter $\mathrm{X}$-band wavelengths (calculated as in Doviak and Zrnic 1993, p. 42). The large X-band attenuation values shown here preclude use of X-band for long-range radar designs, but it is practical to build an adequate margin for attenuation into the radar design when operating at tens of kilometers

ploying large towers to accommodate megawatt-class transmitters and 12-m radomes, dense networks will require deployment on small towers having small land footprints or the use of existing infrastructure elements, such as rooftops, sides of buildings, and communication towers. This requires that the radars be physically small and that the radiated power levels be low enough so as not to pose an actual or perceived radiation safety hazard.

A reasonable size for unobtrusive equipment deployment on existing infrastructure elements is an antenna aperture of $1 \mathrm{~m}$. The aperture size $(d)$ limits the resolution achieved by a radar according to the relationship

resolution $(\mathrm{km})=$ beamwidth $($ radians $) \times$ range $(\mathrm{km})$,

where

$$
\text { beamwidth } \approx \lambda / d .
$$

Operating a radar having a 1-m antenna at S-band $(\lambda=10 \mathrm{~cm})$, the frequency of the WSR-88D NEXRAD system, results in a beamwidth of $5.7^{\circ}$, which corresponds to a $3-\mathrm{km}$ spatial resolution at $30 \mathrm{~km}$ range. ${ }^{5}$ However, sub-kilometer-scale weather features such as tornadoes cannot be resolved at this coarse resolution. By going to a shorter wavelength, the resolution can be improved. Operating the same 1-m antenna at a wavelength of approximately $3 \mathrm{~cm}$ (X-band) reduces the beamwidth to $1.8^{\circ}$ for a spatial resolution of $1 \mathrm{~km}$ at $30-\mathrm{km}$ range. ${ }^{6}$

Short-wavelength (X-band) operation has the benefit of attaining high spatial resolution with a smaller size aperture. Short wavelength $(\lambda \sim 3 \mathrm{~cm})$ operation also takes advantage of enhanced Rayleigh/ Mie scattering from hydrometeors, but at a cost of increased attenuation in the presence of precipitation. Table 1 provides a comparison of attenuation at range. Willie et al. (2006) estimated the actual attenuation that would be experienced as a function of range for X-band radars viewing springtime rainstorms in Oklahoma, with results shown in Fig. 5. Note that the data only include that collected during rainstorms. In particular, the curves show that radars designed for $30-\mathrm{km}$ maximum range will experience two-way attenuation less than $16 \mathrm{~dB}$ for $90 \%$ of springtime rainstorms in Oklahoma. ${ }^{7}$ The corresponding 90\% value for radars designed for $60-\mathrm{km}$ maximum range is $7 \mathrm{~dB}$ higher, at $23 \mathrm{~dB}$. Such an analysis drives consideration of shorter (i.e., moving to the left in Fig. 5) rather than longer (i.e., moving to the right in Fig. 5) separations, and $30 \mathrm{~km}$ has been selected by the CASA project as a starting point for radar design.

Figure 6 combines the attenuation information of Fig. 5 with the other variables needed to perform

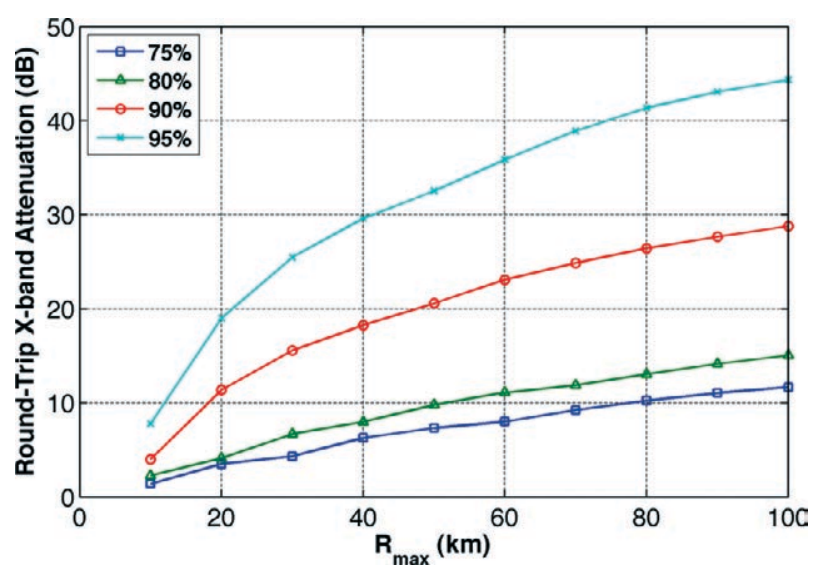

FIG. 5. X-band attenuation statistics for Norman, OK (Willie et al. 2006). Note that the plot only contains data collected when there was rain falling in the coverage domain of the radar. This single-radar attenuation statistic was derived from data from KOUN (a dualpolarized NEXRAD).

\footnotetext{
${ }^{5}$ The important figure of merit here is the resolution achieved in the cross range (i.e., azimuth or elevation) direction because this is the attribute of a radar's spatial resolution that is limited by the physical size of the antenna. Achieving high spatial resolution in the range direction is a relatively simple matter to achieve using modest radar receiver bandwidths.

${ }^{6}$ Signal-processing techniques similar to those being proposed for NEXRAD "super resolution" (Torres and Curtis 2006) can be applied to sharpen this resolution even further.

${ }^{7}$ In Oklahoma, springtime is referred to as "tornado season," with the majority of tornados occurring between March and May.
} 
a standard radar range equation analysis to estimate the measurement sensitivity for radars deployed in networks with $30-\mathrm{km}$ spacing as a function of radar transmitter power. The three curves describe the sensitivity that would be obtained at $30-\mathrm{km}$ range under clear-air conditions (bottom curve, no attenuation) and during precipitation (middle and top curves; attenuation data from Fig. 5). The horizontal axis depicts average transmitted power levels ranging from several hundred milliwatts through $10 \mathrm{~W}$, through $100 \mathrm{~W}$. As a point of reference, $10 \mathrm{~W}$ represents the average power emitted by a moderate-power magnetron transmitter. Such transmitters are small devices (approximately the size of a fist or a human heart) that cost less than $\$ 1,000$. Here, $100 \mathrm{~W}$ represents an estimate of the power level that could be achieved using a low-cost phased-array panel. Absent attenuation, the sensitivity at $30 \mathrm{~km}$ depicted in Fig. 6, ranges between 10 and $0 \mathrm{dBZ}$ for transmitter power levels between 10 and $100 \mathrm{~W}$, respectively.

NETWORKED OPERATION. In current operational weather radar networks, radar coverage is nonoverlapping (except at high altitudes), and the radars are operated largely independent of one another, repeatedly scanning the entire volume around the radar in a "sit and spin" fashion. In contrast, an essential feature of the short-range radars in the dense networks envisioned and described in this paper is to arrange them to have full overlapping coverage so that every location in the network is visible to multiple radars. This requires setting the maximum range of the radars approximately equal to the spacing between the radars. ${ }^{8}$ This permits the use of a radar control architecture that coordinates the beam scanning of the radars in the network both collaboratively - to obtain simultaneous views of a region for data fusion-based algorithms such multiple-Doppler wind field retrievals (discussed in this section) and network-based attenuation correction (see "Open issues" section) — and adaptively to optimize where and how the space over the network is scanned based on the type of weather occurring there and the data product needs of the system's users. The result of this collaborative adaptive sensing approach is network-level performance that exceeds the capabilities of its component radars in terms of update rate on key weather features, minimum beam height, spatial resolution, sensitivity,

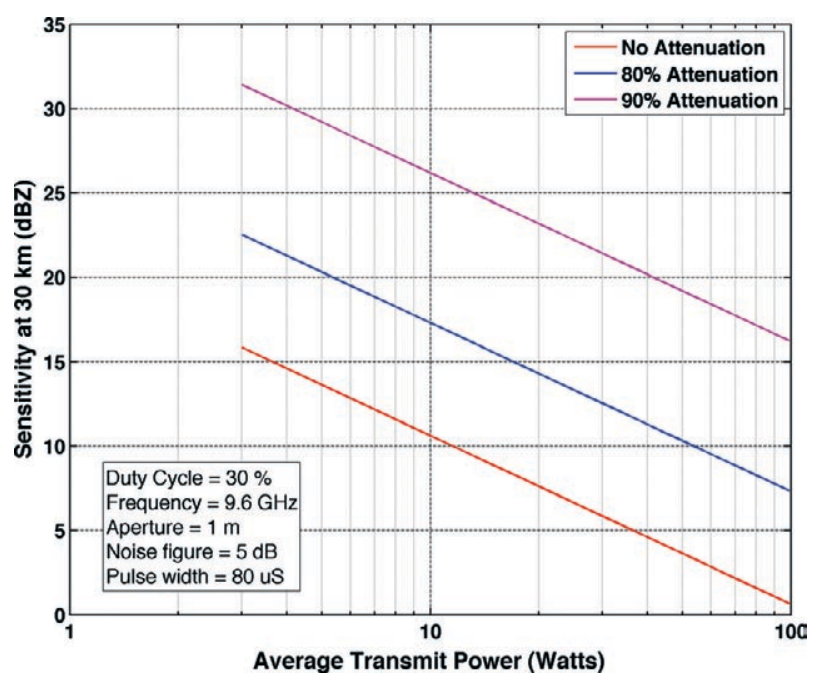

FIG. 6. Sensitivity at $30 \mathrm{~km}$ as a function of transmit power for low-power radar technology. The $\mathbf{8 0} \%$ and $90 \%$ attenuation curves incorporate the attenuation data from Fig. 5 into the radar equation.

attenuation tolerance, and ability to support multiple users and multiple applications. Such network advantages-examples of which are demonstrated in this section-decrease the design requirements on the individual radars that make up the network; that is, key radar size and cost drivers, such as the antenna size and the peak transmitter power needed to achieve a particular level of resolution or sensitivity, are lower than they would need to be if the radars were not part of a collaborative, adaptive network. This concept, which CASA has implemented as a "meteorological command and control" (MCC) software architecture in its Integrative Project One (IP1) demonstration network in Oklahoma, is one of the core enabling technologies behind the dense network approach. This section motivates the collaborative adaptive sensing concept of radar operations, describes the IP1 demonstration network, and gives some examples from the network to illustrate the potential advantages of the dense network collaborative adaptive sensing approach.

Collaborative, adaptive sensing. Under a traditional sit-and-spin concept of radar-operations, the update rate is the same for all locations covered by the radar network. As the number of elevation angles required to cover the volume of interest increases, however, this update rate can become unacceptably

\footnotetext{
${ }^{8}$ Covering the cone of silence above a radar requires that the maximum range be set slightly greater than the radar spacing. This is described in greater detail in McLaughlin et al. (2007). This spacing rule is satisfied by the WSR-88D network in the eastern part of the CONUS, enabling that system to achieve a degree of overlapping coverage at higher altitudes (e.g., $>3 \mathrm{~km}$ ).
} 
long. ${ }^{9}$ On the other hand, it is not necessary to scan all meteorological phenomena at the same update rate nor all in the same way. Powerful supercells within which circulations are rapidly forming and dissipating should be sampled at a much higher rate and with a different scan strategy than, for example, a large-scale, slow-moving stratiform rain event. Working with users of weather radar data-National Weather Service forecasters, emergency managers, and a variety of subject matter experts-CASA has identified update rates and scan strategies for different types of weather phenomena (Philips et al. 2008). To execute these user-defined scan strategies, the MCC in the IP1 demonstration network employs a concept-of-radar-operations based on targeted sector scanning; that is, instead of the radars sitting and spinning, the radars perform back-and-forth, bottom-to-top raster scans of selected subvolumes of the network at update rates that depend on the weather features detected in the volumes. Through such a time-space adaptive, targeted sector-scanning approach; the network achieves update rates on the order of 1-min of those weather features that the system's users have indicated are most important to their data needs. In addition, by optimally selecting which radar(s) is used to scan a given subvolume, the MCC is able to achieve a network-level performance that is better than that of the individual radars that make up the network. In particular, for the IP1 demonstration network where the radars are arranged approximately as equilateral triangles of $30 \mathrm{~km}$ on a side (as will be described shortly), a simple "choose the closest radar" strategy means that no point in the network is farther than $\sim 18 \mathrm{~km}$ from a radar. ${ }^{10}$ For range-dependent performance metrics-such as minimum beam height above ground level and spatial resolution-this leads to a network improvement factor of approximately $40 \%$ over the performance at $30 \mathrm{~km}$. Thus, radars whose beam center and spatial resolution at $30 \mathrm{~km}$ are $500 \mathrm{~m}$ and $1 \mathrm{~km}$, respectively, achieve beam floor and spatial resolu- tion levels no more than 300 and $600 \mathrm{~m}$, respectively, in a network. For performance metrics that depend on the square of the range, such as sensitivity, the network improvement is nearly $65 \%$, or $4.4 \mathrm{~dB}$. Thus, radars having $10-\mathrm{dBZ}$ sensitivity at $30 \mathrm{~km}$ achieve worst-case sensitivity of no more than $6.6 \mathrm{dBZ}$ under networked operation. For the case in which the closest radar might be attenuated-for example, as a result of severe radome wetting or because of intense precipitation between the closest radar and the volume of interest (recall Table 1) - a "choose the least attenuated radar" strategy can be used. The network advantage under such a strategy can be a dramatic reduction in the path attenuation a radar needs to overcome. The study in Chandrasekar et al. (2009b) shows a reduction in the $90 \%$ attenuation margin of almost $10 \mathrm{~dB}$ under networked operation. ${ }^{11}$ In addition to the advantages above, by choosing multiple radars to simultaneously scan a common volume, one obtains the additional advantage of being able to extract data products not easily or as accurately obtained from single-radar measurements, such as the simultaneous measurement of several linearly independent components of the wind for $2 \mathrm{D}$ and 3D wind field estimation (multiple-Doppler wind field retrieval), or the estimation of reflectivity from multiple observations of a common volume along differently attenuated paths (Chandrasekar and Lim 2008). The targeted sector scan approach used by the IP1 MCC is discussed in more detail later. For more rigorous treatments of the principles and advantages of network-based sensing see Junyent and Chandrasekar (2009), Chandrasekcar et al. (2004), Chandrasekar and Jayasumana (2001), and Insanić and Siqueria (2008).

Demonstration network. To investigate the dense network paradigm and collaborative adaptive sensing concept, the participants of the CASA project designed, fabricated, and deployed a four-radar test bed in Oklahoma. This IP1 demonstration network

\footnotetext{
${ }^{9}$ In general, the shorter the operating range of a radar, the larger the number of elevation angles required to meet a given coverage ceiling requirement. For example, for volume coverage up to $21 \mathrm{~km}$ (the coverage ceiling requirement for the current NEXRAD system), the radars in a dense network with 30-km radar spacing would have to cycle through nearly 30 elevation angles. NEXRAD, in contrast, cycles through no more than 14 elevation angles for sit-and-spin volume update rates of between 4 and $5 \mathrm{~min}$.

${ }^{10}$ Here, $18 \mathrm{~km}$ is the distance to the center of an equilateral triangle with side lengths equal to $30 \mathrm{~km}$.

${ }^{11}$ Technically, the range-related performance improvements hold for all points in the network, except the fraction of the volume included in the cone of silence above each radar. Here, overlap is sufficient for a neighbor to cover this region, but there will be no range-related network improvement over a radar's baseline performance at a range equal to the spacing of the radars in the network. However, even for the cone-of-silence regions there can be a reduction in "effective" attenuation and improvement in velocity vector accuracy with judicious choice of which radar(s) performs the scan.
} 
covers a $7,000-\mathrm{km}^{2}$ region in southwestern Oklahoma that receives an average of four tornado warnings and 53 thunderstorm warnings per year (Brotzge 2006). The radars are spaced approximately $30 \mathrm{~km}$ apart and arranged in a topology consisting of back-to-back equilateral triangles, an arrangement chosen because it maximizes the volume of atmosphere around the network satisfying the conditions for dual-Doppler velocity vector retrievals (Brewster et al. 2005). The maximum ranges of the radars are set to $40 \mathrm{~km}$ to provide the overlapping coverage needed for multiple radar measurements and collaborative, adaptive scanning experiments, including the ability of a radar to cover the cone of silence of each of its neighbors. Figure 7 shows the radars in the IP1 test bed along with their coverage range rings. Also

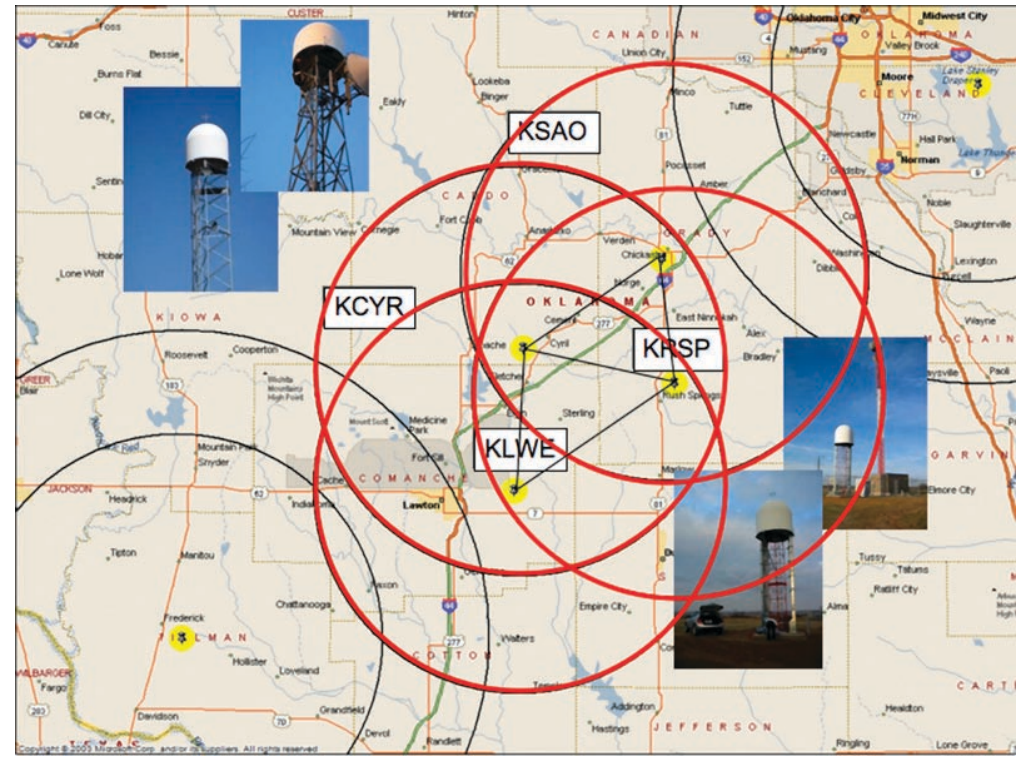

FIG. 7. Map of the CASA IPI test bed in southwestern Oklahoma showing the radar sites and $40-\mathrm{km}$ range rings. Also shown are the NEXRAD radars at (bottom left) Frederick (KFDR) and (top right) Twin Lakes (KTLX). The rings around the NEXRAD radars are at 40 and $60 \mathrm{~km}$, respectively. shown are the two nearest NEXRAD radars: KFDR at Frederick to the southwest and KTLX at Twin Lakes to the northeast. The range rings around these radars at 40 and $60 \mathrm{~km}$, respectively, show that the IP1 network is essentially midway between these two radars in the low-level coverage gap between them. From a larger network perspective, IP1 represents two unit deployment cells in the sense that deployment of larger numbers of radars covering larger spatial domains would be made by replicating the triangular topology shown in Fig. 7.

Figure 8 shows the architecture and major subcomponents of the individual radars in the network (Junyent 2007; Junyent et al. 2005). These radar units are small (1.2-m parabolic dish antenna) and have a short wavelength $(3.2 \mathrm{~cm}, 9.41 \mathrm{GHz}, \mathrm{X}$-band). Using low-power magnetron transmitters $(10 \mathrm{~kW}$ peak, $13 \mathrm{~W}$ average ${ }^{12}$ ), they have a single-pulse sensitivity of $10.8 \mathrm{dBZ}_{\mathrm{h}}$ at $30 \mathrm{~km}$. The radars provide dual-polarization capabilities [simultaneous linear horizontal and vertical; see Bringi and Chandrasekar (2001)] with a dual-polarized waveguide/antenna feedhorn assembly and dual-channel coherent-onreceive receiver/data acquisition system (Khasgiwale et al. 2005). To facilitate targeted sector scanning, the radars sit atop a high-performance pedestal assembly

capable of high accelerations and rapid back-andforth plan position indicator (PPI) sector scanning. A linear actuator attached directly to the antenna provides movement in elevation, including an ability for rapid range-height indicator (RHI) scans. Except for replacing broken parts, the radars can be monitored, maintained, and operated remotely over the Internet. Also, all data are transferred from the radars by Internet links. For perspective, Table 2 compares an IP1 node to a WSR-88D NEXRAD node. CASA's costs to build and operate this network are discussed in the "Open issues" section of this paper.

Running in a UNIX-based computer at each radar is an integrated suite of algorithms for signal processing (short-wavelength range, velocity ambiguity mitigation and attenuation correction, low-level clutter suppression) and polarimetric meteorological moment data estimation (Cho et al. 2005). Table 3 lists the data products generated by the IP1 radars. For velocity ambiguity mitigation, a dual-PRF (pulse repetition frequency) waveform unfolds Doppler velocities up to $\pm 38 \mathrm{~m} \mathrm{~s}^{-1}$ (Bharadwaj and Chandrasekar 2005). For range ambiguity mitigation, an algorithm based on the random phase coding naturally provided by the magnetrons (Siggia 1983) suppresses up to $20 \mathrm{~dB}$

\footnotetext{
${ }^{12}$ This is the total radiated power. The IP1 radars are simultaneous horizontal and vertical (SHV) dual-polarization radars putting out $5.0 \mathrm{~kW}$ peak power per polarization. The duty cycle of the IP1 radars for its dual-PRF "storm" waveform is $0.13 \%$, or $6.5 \mathrm{~W}$ average radiated power per polarization.
} 


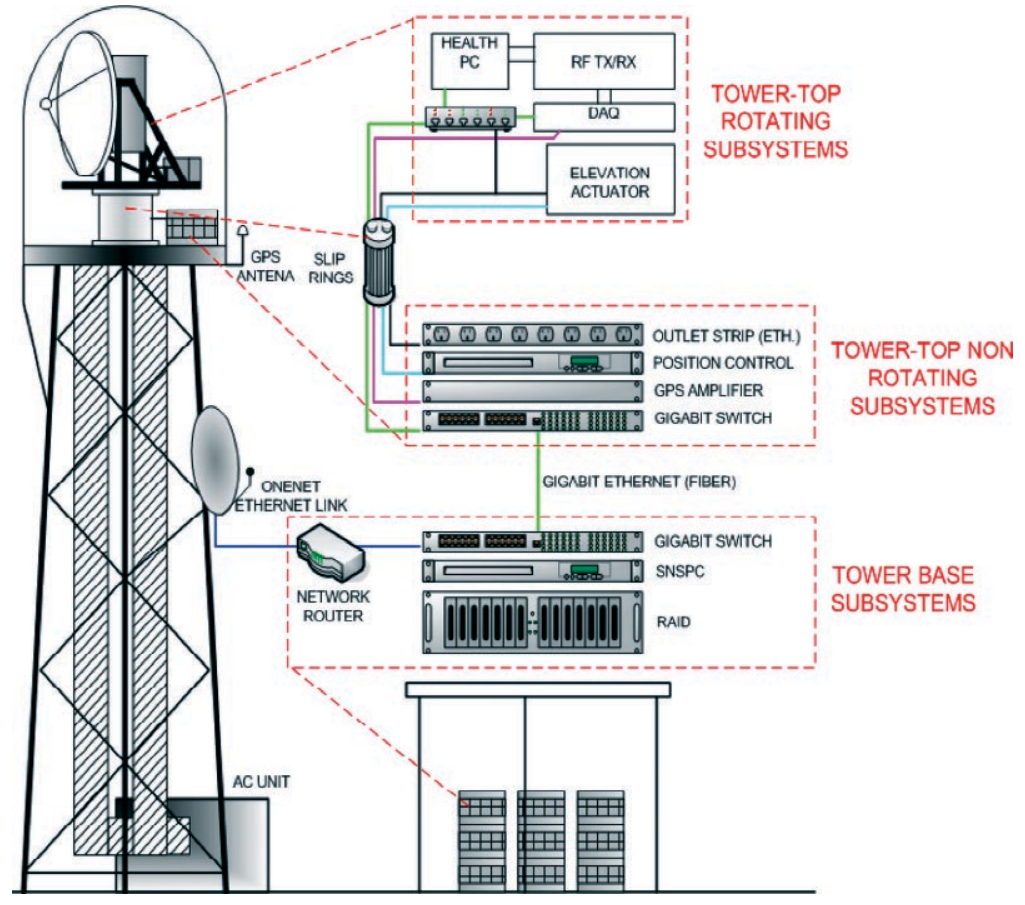

FIG. 8. Architecture of an IPI radar node (from Junyent 2007, p. 49). The tower top rotating assembly contains the radar antenna, transceiver, data acquisition system, and elevation actuator-all mounted on a frame atop the azimuth positioner. On the radome floor, the nonrotating subsystems include a gigabit Ethernet switch, Ethernetcontrolled power outlet strip, GPS amplifier, and position controller computer. A gigabit Ethernet optical fiber links the tower top with the data processing server on the ground. The site is connected to the Internet through a radio link. of overlaid echoes (Bharadwaj and Chandrasekar 2007). The algorithms for clutter suppression and attenuation correction are discussed in the "Open issues" section. Figure 9 from the IP1 radar at Cyril (KCYR) shows the dual-polarization products reflectivity $\left(Z_{\mathrm{h}}\right)$, differential reflectivity $\left(Z_{\mathrm{dr}}\right)$, differential phase $\left(\phi_{\mathrm{dp}}\right)$, and correlation coefficient $\left(\rho_{\mathrm{hv}}\right)$ resulting after ambiguity mitigation, clutter suppression, and attenuation correction.

Meteorological command and control. Collaborative, adaptive sensing in the IP1 network is accomplished using MCC software architecture. As shown in Fig. 10, this architecture "closes the loop" between sensing and radar control; the top part of the loop corresponds to data ingest, the bottom part of the loop corresponds to radar control. To explain, we walk through the five major steps listed in the figure. The first step is the ingest of the data products from the four radars into a data repository. This involves sending the data products

TABLE 2. Specification comparison between the (left) IPI and (right) WSR-88D radars.

\begin{tabular}{|c|c|c|}
\hline Transmitter & Magnetron & Klystron \\
\hline Frequency & 9.4I GHz (X-band) & 2.7-3.0 GHz (S-band) \\
\hline Wavelength & $3.2 \mathrm{~cm}$ & $10 \mathrm{~cm}$ \\
\hline Peak radiated power & $10 \mathrm{~kW}$ & $500 \mathrm{~kW}$ \\
\hline Duty cycle (max) & 0.0013 & 0.002 \\
\hline Average radiated power & $13 \mathrm{~W}$ & $1000 \mathrm{~W}$ \\
\hline Antenna size & $1.2 \mathrm{~m}$ & $8.5 \mathrm{~m}$ \\
\hline Antenna gain & $36.5 \mathrm{~dB}$ & $45.5 \mathrm{~dB}$ \\
\hline Radome size & $2.6 \mathrm{~m}$ & $11.9 \mathrm{~m}$ \\
\hline Polarization & Dual linear, SHV & Single, linear horizontal \\
\hline Beamwidth & $1.8^{\circ}$ & $0.925^{\circ}$ \\
\hline PRF & Dual, I.6-2.4 kHz & Single, $322-1282 \mathrm{~Hz}$ \\
\hline Pulse width & $660 \mathrm{~ns}$ & $1600-4500 \mathrm{~ns}$ \\
\hline Doppler range & $40 \mathrm{~km}$ & $230 \mathrm{~km}$ \\
\hline Range increment & $100 \mathrm{~m}$ & $1000 \mathrm{~m}^{*}$ \\
\hline Azimuth increment & $1^{\circ}$ & $1^{\circ}$ \\
\hline Scan strategy & $\begin{array}{c}60^{\circ}-360^{\circ} \text { adaptive } \mathrm{PPI} \text { sector scans, } 1^{\circ}-30^{\circ} \\
\mathrm{RHI} \text { scans }\end{array}$ & $360 \mathrm{PPI}$ scans, $0.5^{\circ}-19.5^{\circ}$ elevation \\
\hline
\end{tabular}

* The NEXRAD "super resolution" upgrade will reduce the range increment to $250 \mathrm{~m}$ and the azimuth increment to $0.5^{\circ}$. 
TABLE 3. Data products generated by the IPI radars.

\begin{tabular}{|l|c|}
\hline \multicolumn{1}{|c|}{ Variable } & Units \\
\hline Reflectivity & $\mathrm{dBZ}$ \\
\hline Velocity & $\mathrm{m} \mathrm{s}^{-1}$ \\
\hline Spectral width & $\mathrm{m} \mathrm{s}^{-1}$ \\
\hline Differential reflectivity & $\mathrm{dB}$ \\
\hline Differential phase & $\circ$ \\
\hline Cross-polarization correlation & Unitless \\
\hline Normalized coherent power & Unitless \\
\hline Specific phase & rad m ${ }^{-1}$ \\
\hline Horizontal propagation phase & Radians \\
\hline Vertical propagation phase & Radians \\
\hline
\end{tabular}

produced by the IP1 radars in the field, over the Internet, to a system operation and control center (SOCC).$^{13}$ In step 2, the SOCC performs functions of archival and real-time dissemination of data to users. In addition, as data arrives at the SOCC, weather detection algorithms are run on it in real time to identify the locations of significant weather features within the radar network domain. For IP1 these currently include algorithms for reflectivity contouring, storm cell identification, and circulation detection. In step 3 , the detections from the weather detection algorithms are posted in a feature repository. Although Fig. 10 only shows data coming from the IP1 radars, the feature repository can accept detections from other sources, including, for example, NEXRAD or manually entered storm spotter reports. The process of radar control begins in step 4 , where the detected weather features are converted into abstractions called tasks.

In simple terms, a task is a subvolume of the atmosphere identifying where significant weather features are located within the network coverage domain, a classification as to whether or not the feature is

\footnotetext{
${ }^{13}$ The SOCC can physically be located wherever there is an adequate network connection. The IP1 system is typically operated from a SOCC installed in an office in the National Weather Center in Norman, Oklahoma.
}

associated with strong winds or high reflectivity, and a user-assigned value indicating how important it is to scan the task within the next minute. Because there are generally many tasks (i.e., many weather features of potential interest) in the network at any time, an optimization process in step 5 applies a scanning strategy that is a combination of the "pick closest radar/pick least attenuated radar" discussed previously, trading off factors such as the sector sizes to be scanned (in azimuth and elevation) against closeness, signal-tonoise ratio (SNR), the number of tasks to be scanned, the past history of scans, and the values assigned to the tasks by the users of the system (Pepyne et al. 2008; Zink et al. 2008b). The actual commands output from the MCC to the radars are described next.

Performance examples. Since the first multiradar data were ingested from the IP1 network on 9 May 2006, several terabytes of data have been collected and analyzed. This includes an evaluation by NWS forecasters in the NOAA Hazardous Weather Testbed at the National Weather Center in Norman, Oklahoma, during two Oklahoma spring storm seasons (2007
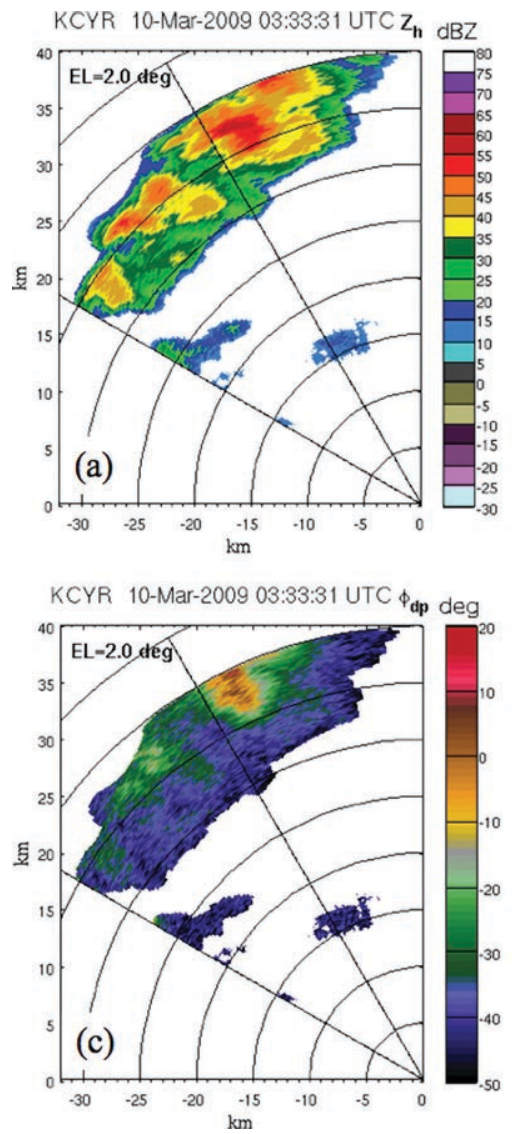

FIG. 9. CASA IPI polarimetric variables: (a) $Z_{h}$, (b) $Z_{d r}$, (c) $\phi_{d p}$, and (d) $\rho_{\mathrm{hv}}$. The CASA IPI radars are SHV dual-polarization Doppler radars. 


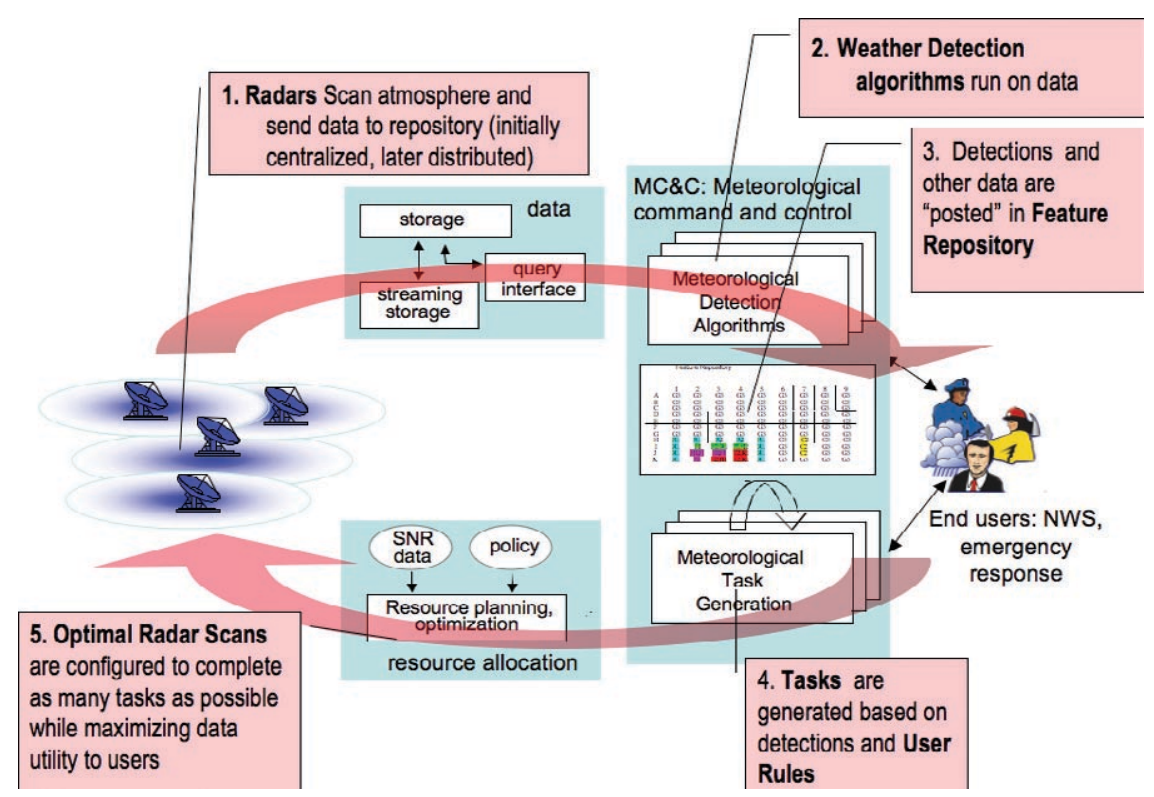

FIG. I0. Flow diagram depicting the major processing steps of the closed-loop MCC software architecture.

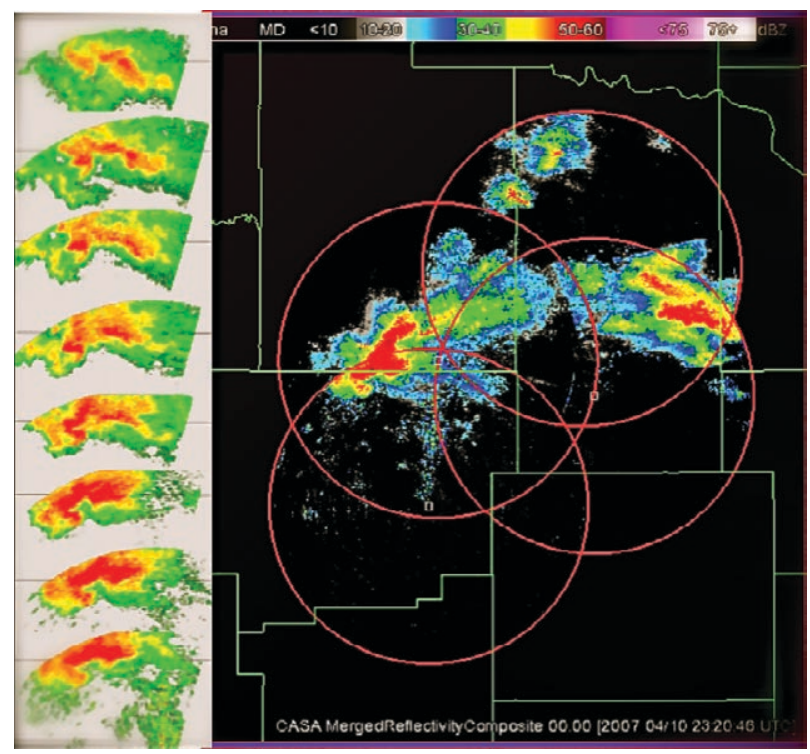

FIG. II. Sequence of sector scans performed around a meteorologically significant feature beginning at $200 \mathrm{~m}$ AGL (lowest scan). (left) The sector scan shows the feature at $1^{\circ}, 2^{\circ}, 3^{\circ}, 5^{\circ}, 7^{\circ}, 9^{\circ}, 11^{\circ}$, and $14^{\circ}$ elevation angle.

and 2008). For these experiments, the MCC operated as follows: Scanning was divided into 1-min intervals (referred to as MCC "heartbeats"). During each such 1-min heartbeat, each radar performed a low-level 360 PPI surveillance sweep at $2^{\circ}(20$ s) followed by a multiple-elevation PPI sector scan targeted on one or more important meteorological phenomenon (40 s). ${ }^{14}$ The orientation and width of the sector in azimuth was determined by the MCC optimization (step 5 in Fig. 10) to cover the meteorological features of interest to the users, whereas the number of elevations scanned within the sector varied with the width of the sector. For example, a $60^{\circ}$ sector included seven elevations, whereas a $180^{\circ}$ sector included only four elevations. The elevation angles used were $1^{\circ}, 3^{\circ}, 5^{\circ}$, $7^{\circ}, 9^{\circ}, 11^{\circ}$, and $14^{\circ}$ for coverage from less than $600 \mathrm{~m}$ to more than $10 \mathrm{~km}$ above ground level. Figure 11 illustrates this combined surveillance and multiple-elevation sector scan strategy. The right side of the figure shows a merged composite reflectivity product of surveillance scans taken of a rapidly evolving supercell with an appendage from a 10 April 2007 severe weather event. ${ }^{15}$ The left side of the figure shows a multiple-elevation sector scan targeted on the appendage, revealing the details of its vertical structure. Both the merged image and the multiple-elevation sector scans can be viewed simultaneously and both are updated each minute as the MCC optimizes radar scans in real time. The high resolution and fast updates offered by a dense network are illustrated in Fig. 12, which compares observations of a hook echo from the IP1 radar at Lawton to observations of the same event from the nearest NEXRAD radar at Fredrick (KFDR). The short-range operation and narrow sector scanning detects finescale features at 200-m altitude that are not visible in the WSR-88D observations and the targeted sector scanning offers update rates 5 times faster on the important weather features (Brotzge et al. 2008). For scanning those volumes of the network visible to multiple radars, the IP1 MCC was designed with a scan optimizer for properly coordinating multiple radars to generate multi-Doppler scans of detected storm cells for multi-Doppler wind field retrieval (Wang et al. 2008).

\footnotetext{
${ }^{14}$ Periodically, the radars also do a 10 -s RHI scan for storm vertical cross-section analysis and storm top finding. When an RHI is performed, the time for PPI sector scanning is reduced from 40 to $30 \mathrm{~s}$.

${ }^{15}$ For this appendage, CASA has visual confirmation of a funnel cloud from a television station storm spotter video.
} 
Figure 13 shoes examples of the resulting wind vector products from the system; algorithms for generating similar wind vectors in near-real-time are being tested (Gao et al. 2008).

Space constraints have only allowed us to illustrate a few examples of the advantages provided by the dense network and collaborative adaptive sensing concepts, but it is becoming clear that the dense network concept is demonstrating performance that goes well beyond the current NEXRAD operational state-of-the-art radar in terms of temporal and spatial resolution, low-altitude coverage, and ability to observe Doppler wind vector fields. A movie showing the IP1 MCC in action can be found at the CASA Web site (http://casa.umass.edu/).

OPEN ISSUES. This section considers cost and phased-array technology for small radars. We also discuss some potential limitations of the small radar network approach, and we summarize some of the ongoing research projects aimed at maturing the concept.

Cost. Radars can be purchased today at prices ranging from $\$ 200$ for automobile collision radar to $\$ 2,000$ to $\$ 20,000$ for marine navigation radars to $\$ 1$ million to $\$ 10$ million for large weather radars to costs in excess of hundreds of millions of dollars for the high-performance radars developed for complex missions in defense and other applications. The cost of a radar is driven both by the volume of radars manufactured and the required performance. The small radars considered for dense networks transmit $<100$-W average microwave power. From the point of view of transmitted power, this puts them in the

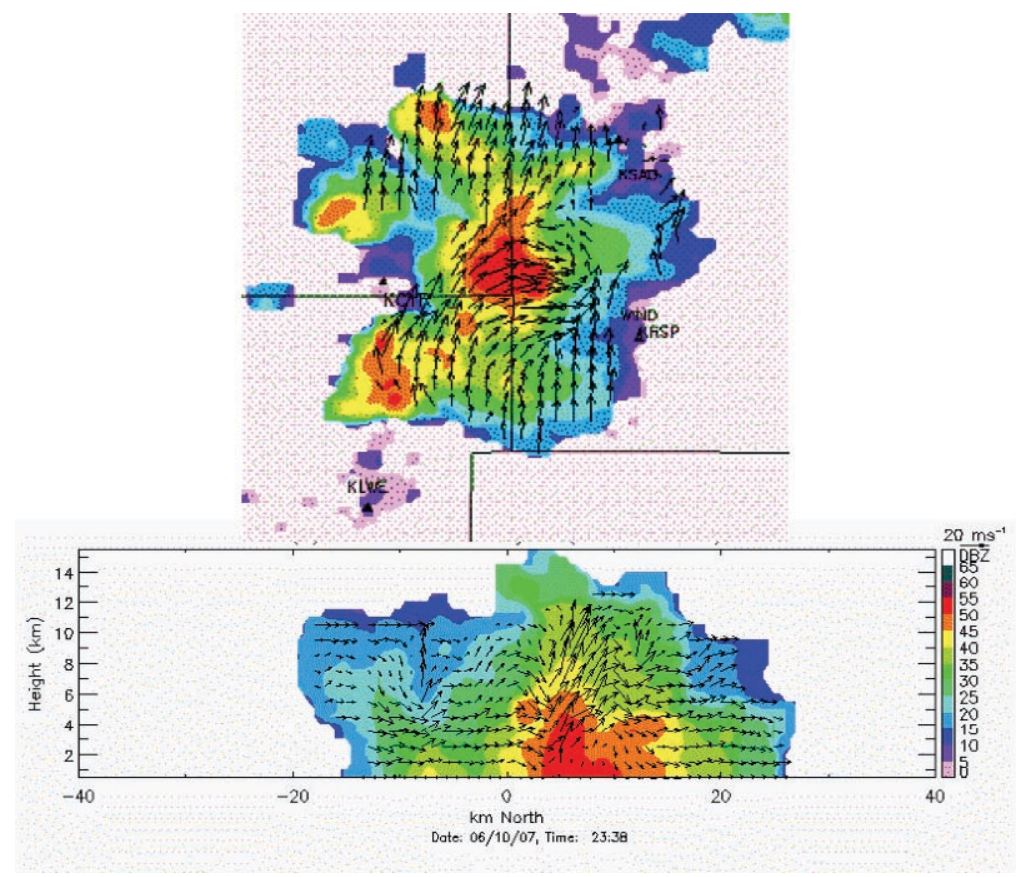

FIG. 13. Three-dimensional wind velocity retrieval from the IPI system. Multiple-Doppler computations have been done with the IPI network down to $200 \mathrm{~m}$ AGL (500 m MSL).

same performance category as the marine radars at the lower end of the price range, and if an opportunity develops to manufacture them in the large numbers 
envisioned in this paper, we anticipate the price to be in the $\$ 200,000$ range. ${ }^{16}$ Although this number is admittedly speculative, CASA's costs to build, install, and operate the radars in the IP1 test bed serves as a useful first data point in projecting costs for this new class of radar. The IP1 radars were designed and fabricated by CASA's academic participants during 2004-05 using a combination of off-the-shelf and custom-made components (Junyent 2007; Khasgiwale et al. 2005). The total parts cost of the transceiver, antenna, computers, and data acquisition system for these dual-polarized, coherent-on-receive radars was $\$ 78,000$. The total parts cost, listed in Table 4 , for all

\begin{tabular}{|c|c|}
\hline \multicolumn{2}{|l|}{ IPI node component costs } \\
\hline Antenna & $\$ 8,000$ \\
\hline Radome & $\$ 20,000$ \\
\hline Tower $(6 \mathrm{~m})^{*}$ & $\$ 15,000$ \\
\hline Data acquisition & $\$ 20,000$ \\
\hline Transceiver & $\$ 30,000$ \\
\hline Elevation positioner & $\$ 10,000$ \\
\hline Azimuth positioner & $\$ 90,000$ \\
\hline Platform, frames & $\$ 10,000$ \\
\hline Computers, storage, networking hardware & $\$ 20,000$ \\
\hline Heating, ventilation, and air conditioning & $\$ 6,000$ \\
\hline Power line & $\$ 500$ \\
\hline Total & $\$ 229,500$ \\
\hline \multicolumn{2}{|c|}{$\begin{array}{l}\text { * The } 20 \text {-m tower at Cyril cost } \$ 120,000 \text {; the site at Chickasha uses an existing } \\
20 \text {-m tower. }\end{array}$} \\
\hline \multicolumn{2}{|l|}{ IPI yearly O\&M costs } \\
\hline Electric power & $\$ 2,000$ \\
\hline Spare parts/repairs & $\$ 7,500$ \\
\hline Networking & $\$ 16,500$ \\
\hline Land lease** & $\$ 0$ \\
\hline Annual total & $\$ 26,000$ \\
\hline
\end{tabular}

components in a complete installation-including the towers, concrete, radomes, environmental and power conditioning, and high-speed antenna positionerswas $\$ 229,500 .{ }^{17}$ With two years of operating experience, CASA's annual operations and maintenance costs, also listed in Table 4 , for each radar is $\$ 26,000$. Several caveats are noted: the IP1 radars were developed by an academic team for use as an experimental research facility, and cost containment was not a strong design driver in realizing this system. These numbers reflect parts costs only, and they exclude labor and other costs associated with manufacturing and selling commercial products; moreover, these represent low-volume costs, given that the CASA project produced only four radars for this test bed.

Phased-array radars. Phased arrays are a key enabling technology in many radars produced for defense applications today, and they are a desirable technology for use in dense radar networks because they do not require maintenance of moving parts, they permit flexibility in beam steering without requiring heavy antenna pedestals such as those used in the CASA IP1 design, and they are more robust with respect to component failure. ${ }^{18}$ Moreover, phased arrays can potentially be mounted to the sides of towers and buildings, as shown in Fig. 14, giving flexibility in the selection of suitable radar sites.

A particular challenge to realizing cost-effective dense networks composed of thou-

\footnotetext{
${ }^{16}$ Here, $\$ 200,000$ is a cost target set by the participants of the CASA project based on both a technology costing exercise and the following calculation: The 156-radar NEXRAD system cost \$1.56 billion to deploy between 1990 and 1997 (OFCM 2006); assuming a $\$ 2$ billion cost to acquire and deploy 10,000 radars for use in a nationwide "blanket deployment" across the CONUS, the per-radar cost would need to be $\$ 200,000$.

${ }^{17}$ One of the four radar installations cost $\$ 80,000$ more than this figure as a result of the construction of a taller, larger capacity tower.

${ }^{18}$ Radar uptime for the 7-week 2007 (9-week 2008) spring storm season was 93\% (94\%). In fact, our biggest reliability problems with IP1 have been with the magnetrons and associated modulator boards, both single-point failures. We admit that this is partially a result of our pushing the capabilities of these low-cost transmitters with dual-PRF waveforms among others, but it also points to the desirability of solid-state radars with their property of "graceful degradation" with array element failure.
} 
sands of phased-array radars will be to achieve a design that can be volume manufactured for $\sim \$ 50,000$ per phased-array panel (assuming four panels per site and assuming each panel is self-contained with the antenna elements and radar transceivers as well as computers for beam steering, data acquisition, and signal processing, communication interfaces, and power conditioning electronics). Establishing the specifications for these arrays is currently a work in progress (e.g., McLaughlin et al. 2007); however, several key parameters can be stated, as listed in Table 5.

Several thousand transmit/receive (T/R) modules are needed to obtain a phased array capable of electronically steering a $2^{\circ}$ beam in two dimensions over the desired scan range without requiring moving parts. Realizing such an antenna requires the use of low-cost microwave semiconductors combined with very low-cost packaging, fabrication, and assembly techniques. Puzella and Alm (2007) and Sarcione et al. (2008) describe an architecture and prototype of a phased array with these characteristics being developed by Raytheon based on manufacturing processes similar to those for making low-cost computer boards. Another approach to realizing these panels is to perform electronic beam steering in the azimuth direction while mechanically steering (tilting) the antenna in the elevation direction. Salazar et al. (2008) describe a prototype version of such an antenna being developed within the CASA center. Because electronic beam steering is only needed in the azimuth direction, the individual panels in this design require only $641-\mathrm{W}$ T/R modules, each of which is estimated to cost $\$ 500$, which, when realized, is expected to result in a cost of less than $\$ 50,000$ per panel (McLaughlin 2008).

Potential limitations. Although this paper argues that dense networks of small radars have the potential to supplement, or perhaps replace, large radars, it is recognized that the concept proposed here is still a research work in progress, and it may ultimately not prove feasible to do all the types of measurements that large radars can perform. Two specific examples in which large radars will outperform small radars are in achieving sensitivity to weak echoes and performing observations over the ocean. In those regions where they have visibility (e.g., above 2-3 km AGL) large high-power radars are capable of achieving higher sensitivity than the small radars described here. Large radars sited near the coast have the ability to observe atmospheric flows as much as $200 \mathrm{~km}$ from the shoreline; this will not be feasible with smaller short-range radars installed on land-based sites.

Ongoing research projects. There are a number of signal processing challenges that need addressing to effectively operate small, low-power, short-wavelength radars at low-elevation angles. Attenuation and clutter 
are two such challenges. Even operating at short range, attenuation introduces errors into estimates of reflectivity that must be accounted for. A dual-polarization attenuation correction is currently employed in IP1 to correct the retrieved radar reflectivity and differential reflectivity in real time (Lim and Chandrasekar 2005; Lim et al. 2007; Liu et al. 2007). Its performance is demonstrated in Fig. 15a, with comparison against NEXRAD observations. Using the capability for simultaneous measurements from multiple radars, a network-based attenuation correction algorithm has also been devised in CASA (Chandrasekar and Lim 2008). This algorithm, which involves the simultaneous solution of a set of integral equations describing the backscatter and propagation properties of a common observation volume, brings the new paradigm of network-based processing and is being evaluated for real-time operation in the IP1 network. To separate ground clutter from weather echoes, various clutter suppression techniques are being explored. The current technique, whose performance is illustrated in Fig. 15b, is a spectral-based approach that suppresses

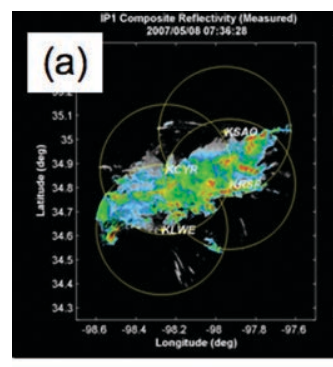

IP1 measured Z

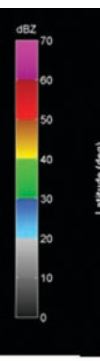

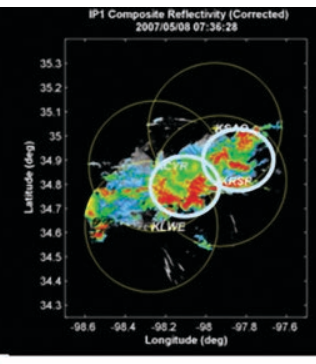

IP1 corrected Z

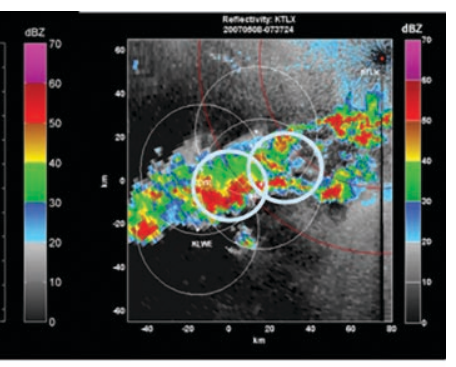

KTLX measured Z

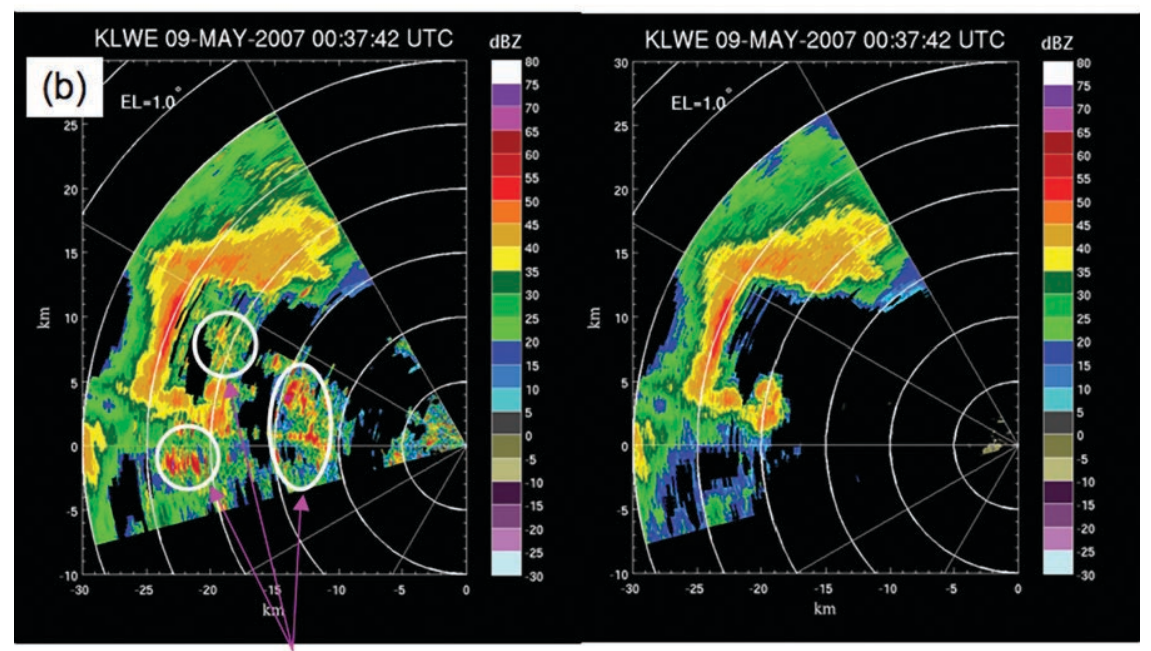

Ground clutter

FIG. 15. Signal processing examples from the CASA's IPI network: (a) comparing CASA's dual-polarization attenuation correction technique with the KTLX NEXRAD radar, and (b) illustrating CASA's ground clutter filtering with adaptive spectral processing. up to $40 \mathrm{~dB}$ of clutter contamination (Moisseev and Chandrasekar 2009; Moisseev et al. 2008). Similar in design to Gaussian model adaptive processing (GMAP; Siggia and Passarelli 2004), the algorithm does not require a clutter map; a property particularly useful under the IP1 targeted sector scan approach. Other techniques are being evaluated, including some of which may more suitable for phased-array radar applications (Nguyen et al. 2008).

A potentially rich application for dense network technology is hydrological forecasting in complex terrain where long-range radars cannot see because of terrain blockage. After several years of in-house study, Météo-France, for example, has chosen to install two-four gap-filling X-band radars in the Tinee and Ubaye River valleys along the eastern border of France to improve hydrological forecasts and flood warning there (Tabary et al. 2008). For quantitative precipitation estimate (QPE), CASA is exploring the use of the specific differential propagation phase $\left(K_{d p}\right)$. Not only does $K_{d p}$ have higher sensitivity at X-band compared to the low-attenuating frequencies ( $\mathrm{C}$ and S-bands), but it is relatively immune to rain attenuation, calibration biases, partial beam blockage, and hail contamination. See Chandrasekar et al. (2009a) for preliminary results on the capabilities and potential of X-band dual-polarization radar networks for flood warning in urban settings where building clutter is an issue.

Controlling, monitoring, assimilating, and disseminating data from 10,000 radars promises to be a major challenge. For radar control in large networks, distributed versions of the MCC described in the "Networked operation" section have been developed in which each radar runs a separate MCC, and the MCC's negotiate with their nearest neighbors to decide which radar(s) should scan each task and how the scan should be performed (Kranin et al. 2007). For 
remote monitoring and management, the radars in the IP1 test bed are all Internet accessible, and the radar software has been configured with various scripts for remote testing and calibration. For getting data to and from the radars, wireless links to the radars, compression schemes for the data, and techniques for needs-based data transmission are being explored ( $\mathrm{Li}$ et al. 2007).${ }^{19}$ For integration with the existing infrastructure, CASA has made its data products compatible with existing NWS formats [network common data form (netCDF), among others] and existing NOAA/ NWS emergency management (EM) visualization tools such as Weather Decision Support System-Integrated Information (WDSS-II) (Lakshmanan et al. 2007) and WeatherScope (http://climate.ok.gove/software/). For Internet operation, CASA has also developed its own custom Web-based visualizations and is working on visualizations for handheld devices for individuals such as emergency managers, tornado spotters, and first responders to use in the field.

Other research within CASA is evaluating the dense network concept through an analysis of the IP1 data. Brotzge et al. (2007) and Chandrasekar et al. (2008) report on the overall operation of the network. Zink et al. (2008a) evaluate the performance of the MCC. Bharadwaj et al. (2007) evaluate the IP1 signal processing waveforms. Data assimilation from CASA is addressed in Brewster et al. (2008). Philips et al. (2008) reports on studies related to identification of user need and user experience with the collaborative adaptive sensing paradigm. Analysis of IP1 tornado detection and forecasting with CASA networks is reported in Brotzge et al. $(2008,2009)$, Chandrasekar et al. (2007), Proud et al. (2008), and Potvin et al. (2009). ${ }^{20}$ The effect of IP1 data on numerical weather prediction (NWP) is explored in Schenkman et al. (2008). Cheong et al. (2008) reports on refractivity measurements conducted at X-band for obtaining low-level moisture fields with such networks.

SUMMARY. Current approaches to operational weather observation are based on the use of physically large, high-power, long-range radars that are blocked from viewing the lower part of the troposphere by the Earth's curvature. This paper describes an alternate approach based on dense networks composed of large numbers of small X-band radars. Spacing these radars tens of kilometers apart defeats the Earth curvature problem and enables the sampling of the full vertical depths of the atmosphere using 1-m antennas and transmitters having only tens of watts of transmitter power. Such networks can provide observing capabilities beyond the operational state of the art while simultaneously satisfying the needs of multiple users. Improved capabilities associated with this technology include low-altitude coverage, subkilometer spatial resolution, rapid update times, and multi-Doppler retrievals of vector winds. This technology has the potential to supplement, or perhaps replace, the widely spaced networks of physically large high-power radars in use today.

ACKNOWLEDGMENTS. This work is supported primarily by the Engineering Research Center program of the National Science Foundation under NSF Cooperative Agreement EEC-0313747. The NSF Program Director for the CASA ERC is Dr. Stephen Nelson. The Leader of the NSF Engineering Research Centers program is Lynn Preston. Any opinions, findings, conclusions, or recommendations expressed in this material are those of the authors and do not necessarily reflect those of the National Science Foundation. CASA is a consortium of academic, government, and industry partners, including the University of Massachusetts at Amherst (lead organization), University of Oklahoma, Colorado State University, University of Puerto Rico at Mayaguez, University of Delaware, University of Virginia, McGill University, Indiana University of Pennsylvania, University of Colorado at Colorado Springs, NOAA/National Weather Service, Department of Energy, OSHRE/OneNet, Raytheon Company, Vaisala, Inc., IBM, DeTect, Inc., EWR Weather Radar, WeatherNews, Inc., ITT Corporation, Environment Canada, KWTV NEWS 9, and the Japan National Research Institute for Earth Science and Disaster Prevention (NIED).

\section{REFERENCES}

Bharadwaj, N., and V. Chandrasekar, 2005: Waveform design for CASA X-band radars. Preprints, 32nd Conf. on Radar Meteorology, Albuquerque, NM, Amer. Meteor. Soc., P10R.13. [Available online at http:// ams.confex.com/ams/32Rad1Meso/techprogram/ paper_96347.htm.]

\footnotetext{
${ }^{19}$ Estimating the meteorological moments at the radars themselves, rather than shipping the in-phase $(I)$ and quadrature $(Q)$ data from the radars for such estimation, is equivalent to about a 100:1 compression ratio over the raw radar data.

${ }^{20}$ During the 2007 spring experiment, two confirmed tornadoes occurred within the coverage domain of the IP1 test bed. However, despite a record number of tornadoes in the United States in 2008, none occurred in the IP1 test bed domain. The IP1 test bed detected both of the 2007 tornadoes.
} 
— and _ - 2007: Phase coding for range ambiguity mitigation in dual-polarized Doppler weather radars. J. Atmos. Oceanic Technol., 24, 1351-1363.

- - — , and F. Junyent, 2007: Evaluation of first generation CASA radar waveforms in the Ip1 testbed. Preprints, IEEE Int. Geoscience and Remote Sensing Symp., Barcelona, Spain, Geoscience and Remote Sensing Society, 2742-2745.

Brewster, K. A., L. White, B. Johnson, and J. Brotzge, 2005: Selecting the sites for CASA NetRad, a collaborative radar network. Preprints, Ninth Symp. on Integrated Observign and Assimilation Systems for the Atmospheres, Oceans, and Land Surface, San Diego, CA, Amer. Meteor. Soc., P3.4.[Available online at http://ams.confex.com/ams/Annual2005/ techprogram/paper_86635.htm.]

_, J. Brotzge, K. W. Thomas, Y. Wang, M. Xue, J. Gao, and D. Weber, 2008: High resolution assimilation of CASA and NEXRAD radar data in near-real time: Results from spring 2007 and plans for spring of 2008. Preprints, 12th Conf. on Integrated Observing and Assimilation Systems for the Atmosphere, Oceans, and Land Surface, New Orleans, LA, Amer. Meteor. Soc., 15B7. [Available online at http://ams.confex. com/ams/88Annual/techprogram/paper_132983. htm.]

Bringi, V. N., and V. Chandrasekar, 2001: Polarimetric Doppler Weather Radar: Principles and Applications. Cambridge University Press, 636 pp.

Brotzge, J., 2006: Severe weather climatology of IP1. CASA Tech. Rep, Oklahoma University Rep., 8 pp. [Available from J. Brotzge, University of Oklahoma, 120 David L. Boren Blvd., Norman, OK 73072 7309.]

— tions and initial data. Preprints, $23 \mathrm{rd}$ Conf. on Interactive Information Processing Systems for Meteorology, Oceanography, and Hydrology, San Antonio, TX, Amer. Meteor. Soc. 8A.6. [Available online at http:// ams.confex.com/AMS/87ANNUAL/techprogram/ paper_120056.htm.]

—, D. Andra, K. Hondl, and L. Lemon, 2008: A case study evaluating Distributed Collaborative Adaptive Sensing: Analysis of the 8 May 2007 minisupercell event. [Available online http://ams.confex.com/ ams/88Annual/techprogram/paper_132909.htm.]

— , K. Hondl, B. Philips, L. Lemon, E. Bass, D. Rude, and D. Andra Jr., 2009: Evaluation of Distributed Collaborative Adaptive Sensing for detection of lowlevel circulations and implications for severe weather warning operations. Wea. Forecasting, in press.

Chandrasekar, V., and A. P. Jayasumana, 2001: Radar design and management in a networked environ- ment. Technologies, Protocols, and Services for Next-Generation Internet, A. Jayasumana and V. Chandrasekar, Eds., International Society for Optical Engineering (SPIE Proceedings, Vol. 4527), 125-133. - , and S. Lim, 2008: Retrieval of reflectivity in a networked radar environment. J. Atmos. Oceanic Technol., 25, 1755-1767.

— — - N. Bharadwaj, W. Li, D. McLaughlin, V. N. Bringi, and E. Gorgucci, 2004: Principles of networked weather radar operation at attenuating frequencies. Proc. Third European Conf. on Radar in Meteorology and Hydrology (ERAD) Visby, Sweden, Copernicus GmbH, 109-114.

—, D. McLaughlin, J. Brotzge, M. Zink, B. Philips, and Y. Wang, 2007: Distributed Collaborative Adaptive radar network: The CASA IP-1 network and tornado observations. Preprints, 33rd Conf. Radar Meteorology, Cairns, QLD, Australia, Amer. Meteor. Soc., 13A.3A. [Available online at http://ams.confex.com/ ams/33Radar/techprogram/paper_128257.htm.]

,,,,----- , - and,- 2008 : Distributed Collaborative Adaptive Radar network: Preliminary results from the CASA IP1 testbed. Proc. IEEE Radar Conf. Rome, Italy, IEEE Aerospace and Electronics Systems Society, 1-5.

— , M. Maki, Y. Wang, and K. Nakane, 2009a: Considerations for urban floods monitoring using X-band dual-polarization radar network. Preprints, $23 \mathrm{rd}$ Conf. on Urban High Impact Weather, Phoenix, AZ, Amer. Meteor. Soc., J8.3. [Available online at http://ams.confex.com/ams/89annual/techprogram/ paper_149628.htm.]

— , D. Willie, Y. Wang, and S. Lim 2009b: Attenuation margin requirements in a networked radar system for observation of precipitation. IEEE Int. Geoscience and Remote Sensing Symp., Cape Town, Africa, Geoscience and Remote Sensing Society, 1-3.

Cheong, B., R. Palmer, C. Curtis, T. Yu, D. Zrnic, and D. Forsyth, 2008: Refractivity retrieval using the Phased-Array Radar: First results and potential for multimission operation. IEEE Trans. Geosci. Remote Sens., 46, 2527-2537.

Cho, Y.-G., N. Bharadwaj, V. Chandrasekar, M. Zink, F. Junyent, E. Insanić, and D. J. McLaughlin, 2005: Signal processing architecture for a single radar node in a networked radar environment (NETRAD). Proc. IEEE Int. Geoscience and Remote Sensing Symp., Seoul, South Korea, Geoscience and Remote Sensing Society, 3477-3480.

Department of Defense, 2005: Strategy for homeland defense and civil support. DOD Rep. 46 pp. [Available online at www.defenselink.mil/news/Jun2005/ d20050630homeland.pdf.] 
Doviak, R. J., and D. S.Zrnic, 1993: Doppler Weather Radar Observations. 2nd ed. Dover Publications, 562 pp.

Gao, J., K. Brewster, Y. Wang, K. Thomas, J. Brotzge, and M. Xue, 2008: High-resolution three-dimensional wind analysis of CASA IP-1 and WSR-88D radar data using the ARPS 3DVAR. Preprints, 12th Conf. on Integrated Observing and Assimilation Systems for the Atmosphere, Ocean, and Land Surface, New Orleans, LA, Amer. Meteor. Soc., 16.5. [Available online at http://ams.confex.com/ams/88Annual/ techprogram/paper_135080.htm.]

Insanić, E., and P. Siqueira, 2008: Use of vector estimate accuracy for improved resource allocation in a network of radars. Proc. IEEE Int. Geoscience and Remote Sensing Symp., Boston, MA, Geoscience and Remote Sensing Society, 1123-1126.

Junyent, F., 2007: Networked weather radar system using coherent on receive technology. Ph.D. dissertation, University of Massachusetts, $140 \mathrm{pp}$.

- and V. Chandrasekar, 2009: Theory and characterization of weather radar networks. J. Atmos. Oceanic Technol., 26, 474-491.

— - and Coauthors, 2005: Salient features of radar nodes of the first generation NetRad System. Proc. IEEE Int. Geoscience and Remote Sensing Symp., Seoul, South Korea, Geoscience and Remote Sensing Society, 4 pp.

Khasgiwale, R., L. Krnan, A. Perinkulam, and R. Tessier, 2005: Reconfigurable data acquisition system for weather radar applications. Preprints, 48th Midwest Symp. on Circuits and Systems, Covington, KY, IEEE, 822-825.

Krainin, M., B. An, and V. Lesser, 2007: An application of automated negotiation to distributed task allocation. Proc. Int. Conf. on Intelligent Agent Technology, Silicon Valley, CA IEEE, 138-145.

Kurose, J., E. Lyons, D. McLaughlin, D. Pepyne, B. Philips, D. Westbrook, and M. Zink, 2006: An end-user-responsive sensor network architecture for hazardous weather detection, prediction, and response. Proc. Second Asian Internet Engineering Conf., Pathumthani, Thailand, Asian Institute of Technology, $15 \mathrm{pp}$.

Lakshmanan, V., T. M. Smith, G. J. Stumpf, and K. D. Hondl, 2007: The Warning Decision Support System-Integrated information. Wea. Forecasting, 22, 596-612.

Leone, D. A., R. M. Endlich, J. Petriceks, R. T. H. Collis, and J. R. Porter, 1989: Meteorological considerations used in planning the NEXRAD network. Bull. Amer. Meteor. Soc., 70, 4-13.

Li, M., T. Yan, D. Ganesan, E. Lyons, P. Shenoy, A. Venkataramani, and M. Zink, 2007: Multi-user data sharing in radar sensor networks. Proc. Fifth Int. ACM Conf. on Embedded Networked Sensor Systems, Sydney, NSW, Australia, Association for Computing Machinery, 247-260.

Lim, S., and V. Chandrasekar, 2005: An improved attenuation correction algorithm using dual-polarization radar observations of precipitation. Proc. IEEE Int. on Geoscience and Remote Sensing Symp., Seoul, South Korea, Geoscience and Remote Sensing Society, 5100-5103.

,- - P. Lee, and A. P. Jayasumana, 2007: Reflectivity retrieval in a networked radar environment: Demonstration from the CASA IP1 radar network. Proc. IEEE Int. Geoscience and Remote Sensing Symp., Barcelona, Spain, Geoscience and Remote Sensing Society, 3065-3068.

Liu, Y., Y. Wang, D. Willie, V. Chandrasekar, and V. N. Bringi, 2007: Operational evaluation of the real-time attenuation correction system for CASA IP1 testbed. Preprints, 33rd Conf. on Radar Meteorology, Cairns, QLD, Australia, Amer. Meteor. Soc., P7.9. [Available online at http://ams.confex.com/ams/33Radar/ techprogram/paper_123678.htm.]

Maddox, R. A., J. Zhang, J. J. Gourley, and K. W. Howard, 2002: Weather radar coverage over the contiguous United States. Wea. Forecasting, 17, 927-934.

McLaughlin, D. J., 2008: CASA Update for NEXRAD TAC. Briefing to the NEXRAD Technical Advisory Committee, MIT Lincoln Laboratory Rep.

— - and Coauthors, 2005: Distributed Collaborative Adaptive Sensing (DCAS) for improved detection, understanding, and predicting of atmospheric hazards. Preprints, Ninth Symp. on Integrated Observating and Assimilation Systems for the Atmosphere, Oceans, and Land Surface, San Diego, CA, Amer. Meteor. Soc., 11.3. [Available online at http:// ams.confex.com/ams/Annual2005/techprogram/ paper_87890.htm.]

—, E. A. Knapp, Y. Yang, and V. Chandrasekar, 2007: Distributed weather radar using X- band active arrays. Preprints, IEEE Radar Conf., Boston, MA, IEEE Aerospace and Electronics Systems Society, $11-24$.

Moisseev, D. N., and V. Chandrasekar, 2009: Polarimetric spectral filter for adaptive clutter and noise suppression. J. Atmos. Oceanic Technol., 26, 215-228.

—, C. M. Nguygen, and V. Chandrasekar, 2008: Clutter suppression for staggered PRT waveforms. J. Atmos. Oceanic Technol., 25, 2209-2218.

National Research Council, 1995: Toward a New Weather Service: Assessment of NEXRAD Coverage and Associated Weather Services. National Academies Press, $104 \mathrm{pp}$. 
- 2002: Weather Technology Beyond NEXRAD. National Academies Press, 81 pp.

- 2004: Where the Weather Meets the Road: A Research Agenda for Improving Road Weather Services. National Academies Press, 174 pp.

—, 2008: Evaluation of the Multifunction Phased Array Radar Planning Process. National Academies Press, 79 pp.

_-, 2009: Observing Weather and Climate from the Ground Up: A Nationwide Network of Networks. National Academies Press, 250 pp.

Nguyen, C. M., D. N. Moisseev, and V. Chandrasekar, 2008: A parametric time domain method for spectral moment estimation and clutter mitigation for weather radars. J. Atmos. Oceanic Technol., 25, 83-92.

OFCM, 2006: Federal Research and Development Needs and Priorities for Phased Array Radar. Office of the Federal Coordinator for Meteorological Services and Supporting Research Rep. FCM-R25-2006, 16 pp.

Pepyne, D., D. Westbrook, B. Philips, E. Lyons, M. Zink, and J. Kurose, 2008: Distributed Collaborative Adaptive Sensing networks for remote sensing applications. Proc. Amer. Control Conf., Seattle, WA, American Automatic Control Council, 4167-4172.

Philips, B., and Coauthors, 2007: Integrating end user needs into system design and operation: The Center for Collaborative Adaptive Sensing of the Atmosphere (CASA). Preprints, 16th Conf. on Applied Climatology, San Antonio, TX, Amer. Meteor. Soc., 3.14. [Available online at http://ams.confex.com/ ams/87Annual/techprogram/paper_119996.htm.]

— D. Destbrook, D. Pepyne, E. Bass, D. Rude, and J. Brotzge, 2008: User evaluations of adaptive scanning patterns in the CASA Spring Experiment 2007. IGARSS.[Available online at www.igarss08.org/ Abstracts/pdfs/4027.pdf.]

Potvin, C. K., A. Shapiro, T.-Y. Yu, J. Gao, and M. Xue, 2009: Using a low-order model to detect and characterize tornadoes in multiple-doppler radar data. Mon. Wea. Rev., 137, 1230-1249.

Proud, J. L., K. Droegemeier, V. Wood, and R. Brown, 2008: Sampling strategies for tornado and mesocyclone detection using dynamically adaptive Doppler radars: A simulated study. J. Atmos. Oceanic Technol., 26, 492-507.

Puzella, A., and R. Alm, 2008: Air-cooled, active transmit/receive panel array. Proc. IEEE Radar Conf., Rome, Italy, IEEE Aerospace and Electronics Systems Society.

Salazar, J. L., R. Medina, E. J. Knapp, and D. J. McLaughlin, 2008: Phase-tilt array antenna design for dense distributed radar network for weather sensing. IGARSS. [Available online at www.igarss08. org/Abstracts/pdfs/3728.pdf.]

Sarcione, M., N. Kolias, M. Booen, D. McLaughlin, F. Chang, and A. Hajimiri, 2008: Looking ahead: The future of RF technology, military and homeland perspectives. Microwave J., 51, 52-62.

Schenkman, A., A. Shapiro, K. Brewster, M. Xue, J. Gao, and N. Snook, 2008: High resolution assimilation of CASA radar data from a tornadic convective system. Preprints, Symp. on Recent Developments in Atmospheric Applications of Radar and Lidar, New Orleans, LA, Amer. Meteor. Soc., P1.6. [Available online at http://ams.confex.com/ams/88Annual/ techprogram/paper_132040.htm.]

Serafin, R. J., and J. W. Wilson, 2000: Operational weather radar in the United States: Progress and opportunity. Bull. Amer. Meteor. Soc., 81, 809-824.

Siggia, A., 1983: Processing phase-coded radar signals with adaptive digital filters. Preprints, 21st Conf. on Radar Meteorology, Edmonton, AB, Canada, Amer. Meteor. Soc., 513-518.

—_, and J. R. Passarelli Jr., 2004: Gaussian model adaptive processing (GMAP) for improved ground clutter cancellation and moment calculation. Proc. Third European Conf. on Radar in Meteorology and Hydrology, Visby, Sweden, Copernicus GmBH, 67-73.

Tabary, P., J. Parent-du-Châtelet, M. Franco, R. Cremonini, C. Ciotti, and G. Vulpiani, 2008: Overview of the weather radar networks and products in the "north-western" Mediiterranean region (Spain, France and Italy). [Available online at www. hymex.org/global/documents/June2008_workshop/0406_ST2_1_P._Tabary.pdf.]

Torres, S., and C. Curtis, 2006: Design considerations for improved tornado detection using superresolution data on the NEXRAD network. Proc. Fourth European Conf. on Radar in Meteorology and Hydrology, Barcelona, Spain, Servei Meteorològic de Catalunya.

Wang, Y., V. Chandrasekar, and B. Dolan, 2008: Development of scan strategy for dual Doppler retrieval in a networked radar system. IGARSS. [Available online at www.igarss08.org/abstracts/pdfs/3999.pdf.]

Westrick, K. J., C. F. Mass, and B. A. Colle, 1999: The limitations of the WSR-88D radar network for quantitative precipitation measurement over the costal western United States. Bull. Amer. Meteor. Soc., 80, 2289-2209.

Willie, D., W. Li, Y. Wang, and V. Chandrasekar, 2006: Attenuation statistics for X-band radar design. Proc. IEEE Int. Geosciences and Remote Sensing Symp., Denver, CO, Geosciences and Remote Sensing Society, 5077-5080. 
Zink, M., E. Lyons, D. Westbrook, D. Pepyne, B. Philips, J. Kurose, and V. Chandrasekar, 2008a: Meteorological command \& control: Architecture and performance evaluation. IGARSS. [Available online at www.igarss08.org/Abstracts/pdfs/3976.pdf.]
,,--- , J. Kurose, and D. Pepyne, 2008b: Closed-loop Architecture for Distributed Collaborative Adaptive Sensing of the Atmosphere: Meteorological Command \& Control. Int. J. Sens. Networks, in press.

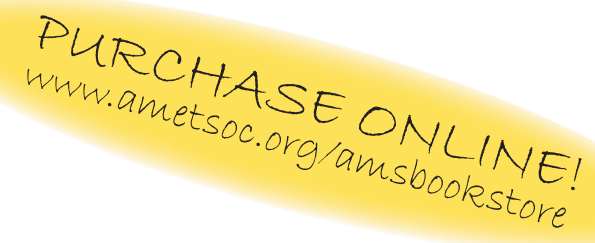

